Abstracta Iranica Abstracta Iranica

Revue bibliographique pour le domaine irano-aryen

Volume 22 | 2001

Comptes rendus des publications de 1999

\title{
Räsmolkhättimiz Häqqindä. Äsmär, Täbriz, 2000, 160 p. [À propos de notre orthographe]
}

\section{Sonel Bosnali}

\section{(2) OpenEdition}

1 Journals

Édition électronique

URL : http://journals.openedition.org/abstractairanica/36215

DOI : 10.4000/abstractairanica.36215

ISSN : 1961-960X

\section{Éditeur :}

CNRS (UMR 7528 Mondes iraniens et indiens), Éditions de l'IFRI

\section{Édition imprimée}

Date de publication : 15 mai 2001

ISSN : 0240-8910

\section{Référence électronique}

Sonel Bosnali, «Räsmolkhättimiz Häqqindä. Äsmär, Täbriz, 2000, 160 p. [À propos de notre orthographe] », Abstracta Iranica [En ligne], Volume 22 | 2001, document 71, mis en ligne le 15 février 2010, consulté le 12 octobre 2020. URL : http://journals.openedition.org/abstractairanica/36215 ; DOI : https://doi.org/10.4000/abstractairanica.36215

Ce document a été généré automatiquement le 12 octobre 2020.

Tous droits réservés 


\title{
Räsmolkhättimiz Häqqindä. Äsmär, Täbriz, 2000, 160 p. [À propos de notre orthographe]
}

\author{
Sonel Bosnali
}

1 Au lendemain de l'adoption, après bien des discussions, de l'alphabet latin par les autres peuples turcophones de la région (Azerbaïdjan, Turkménistan, Ouzbékistan, Kazakhstan et Kirghizistan), les turcophones iraniens se sont mis à la recherche d'une solution à leurs problèmes orthographiques, dont le point culminant fut en juin 2000, à Téhéran, le congrès sur « alphabet et orthographe du turc d'Iran ». Dans ce contexte, le livre de Sälimi, qui se veut un ensemble de réflexions sur la question et dont l'objectif est de proposer des solutions, est une excellente source pour prendre connaissance de l'historique de la question d'alphabet et d'orthographe, des tentatives et des tendances actuelles, ainsi que des difficultés rencontrées dans ce domaine.

2 Tout au long de son livre, l'A. va et vient de la description et la critique de l'orthographe turque employée actuellement dans les différents ouvrages publiés en Iran, pour tirer enfin ses propres conclusions. L'A. présente tout d'abord l'utilisation historique de l'alphabet arabe pour les langues turco-persane afin d'attirer l'attention sur sa place "traditionnelle » et son caractère "sacré » chez ces peuples. Il décrit ensuite la situation " anarchique » dans laquelle se trouve actuellement l'orthographe de la langue turque et tente de l'expliquer. Elle est due, selon l'A., d'une part, à « la situation politique à l'époque des Pahlavi, ayant empêché le développement d'une orthographe adaptée à la langue turque » et d'autre part, à « la tendance de certains auteurs turcophones à imiter les pratiques orthographiques en usage en République d'Azerbaïdjan et en Turquie et à calquer les règles en vigueur dans ces pays ».

3 L'A. mène une étude critique des pratiques orthographiques «irresponsables » de certains auteurs, tenus comme « responsables de la situation anarchique où chacun écrit comme il souhaite ». Il cite des exemples de ces pratiques, notamment celles de deux auteurs connus, Behzad Behzadi et Dashqïn, chacun ayant publié un dictionnaire $\mathrm{du}$ turc en adoptant des règles tout à fait différentes, (Azerbayjan dilinin izahlï lügäti, 
Azärbayjanja-Farsja Sözlük). L'A. leur reproche d'avoir employé «l'alphabet phonétique ». Une série de rappels sur « les différences entre l'alphabet phonétique et l'alphabet graphique » occupe le chapitre suivant.

4 L'A. présente également les travaux précédemment effectués dans ce domaine, (ouvrage de Zähtabi, Anadilimizi näjä yazaq [Comment écrire notre langue maternelle, Tabriz, 1981] et celui de Hamid Notqi, Yazï qaydalarï [Les règles d'orthographe, Varlïq, Téhéran, 1987]), à partir desquels il formule ses propositions. Sans oublier, bien entendu, de citer Mīrzā Fatḥ'alī ÂHūundzāde, qui, déjà au $19^{\mathrm{e}}$ s., estimait l'alphabet arabe incompatible avec les langues turques et proposait une réforme radicale de cet alphabet ou son abandon pur et simple.

5 L'A. tente ensuite de démontrer que l'alphabet arabe possède tous les caractères de compatibilité avec les langues turques, à condition de le perfectionner et de le régulariser par une réforme toute simple. L'adoption de quatre critères suffirait à réaliser cette réforme : " fidélité à l'histoire et à la tradition musulmanes (écrire les mots empruntés à l'arabe et au persan dans leur forme originelle, puisque, en tant que patrimoine culturel, ils sont déjà connus par tous), indépendance par rapport aux règles orthographiques appliquées pour les alphabets cyrillique et latin (ne pas calquer les règles sur celles de ces langues), utilisation des caractéristiques des langues turques et de l'alphabet arabe (emploi des lettres " $s$ emphatique " et " $t$ emphatique " pour les mots possédant des voyelles postérieures), intérêt pour l'esthétique de la graphie et la facilité de lecture, nécessitant l'économie de lettres (emploi du tashdid et des diacritiques)».

6 Le livre de Sälimi montre non seulement l'état du processus de codification de la langue, avec toutes ses divergences, mais aussi l'importance de la question d'alphabet qui se pose également en Iran, quoique d'une manière tout à fait différente.

\section{INDEX}

Thèmes : 2.2. Langues vivantes et dialectes

\section{AUTEURS}

SONEL BOSNALI

IFRI - Téhéran 